\title{
Raising awareness of quality in the NHS
}

\author{
Kenneth C Calman
}

The pursuit of better quality underpins all the changes being made in the NHS; quality is not just a professional or clinical issue but one spanning the whole range of activities embodied in the health service, and awareness of quality is growing.

This paper reviews the developments building on the three key components of the secretary of state's quality framework namely, attention to the real needs of patients, making purchasing more effective, and getting providers to sign up to hard quality criteria. Real progress is being made in each of these as a result of building on the firm base provided by:

- Increasing translation of research findings into practice

- Delivery of more effective clinical practice through the contracting process and through audit

- Greater partnership between managers and professionals.

There are many examples of the new "quality awareness" in action. In the past two years a series of initiatives designed to demonstrate the potential for quality improvement has been networked and disseminated for maximum impact.

\section{Initiatives for quality improvement}

One of the most important initiatives was the "Quality Roadshow," which toured the country in the first part of 1993. As well as celebrating the initiatives on display, it inspired some of the thousands of NHS staff who visited it to adopt ideas relevant to their own experience. In particular it took ideas within reach of many people who, although interested in quality, have few opportunities to step back from the day to day demands of their jobs.

As part of a national programme of demonstration projects the Department of Health funded between 1989 and 1992 eight projects in accident and emergency medicine, 10 in outpatient departments, and four in day surgery at a total cost of over $£ 4 \mathrm{~m}$. The results, which were widely available, showed the range of improvements possible in the organisation of services, the environment within which they were delivered, and the clear potential for making major improvements at relatively little cost. The other part of the national demonstration programme involved initiatives in total quality management. Between 1989 and 1993, 21 projects funded by the department at a cost of $£ 2.6 \mathrm{~m}$, whose approaches were characterised by promoting excellence, customer care initiatives, commitment of top management, and participation (and empowerment) of staff at all levels, were used to test out the value of total quality management to the NHS. The findings, reported in The Quality fourney and forming source material for the Quality in Action training pack for senior managers, undoubtedly provided some valuable generic lessons.

Author initiative was The $A-Z$ of Quality: a Guide to Quality Initiatives in the NHS, launched in September 1993 and describing some of the best initiatives in Britain. Detailing 370 initiatives from over 2500 submitted, covering topics such as clinical services, audit systems, organisation, and patient centred services, this guide has captured the type of exemplars which have the potential for major impact on the health service. Striking examples include the significant reduction in the prevalence of sores achieved in Castle Hill Hospital in Humberside and various approaches to managing acute pain, as illustrated at the Royal Brompton National Heart and Lung Hospital.

The more recent launch of the first series of patient perception booklets was part of the same initiative to keep quality high on the agenda. Covering eczema, haemophilia, breast cancer, fracture clinics, dementia, maternity services for Asian women, access to health services for people with learning disabilities, and sickle cell anaemia, the booklets are designed to help purchasers take account of users' views in their quest for high quality services. The patients' quotes make for uncomfortable reading, but the frank appraisal by users of the health service is necessary and welcome.

The Priorities and Planning Guidance which was issued in June 1993 contained for the first time a significant statement about quality: "NHS Authorities and Trusts should demonstrate an organisation-wide approach to quality through the development of quality improvement strategies which should be made explicit in business plans, specify continuously reviewable standards for services, and require changes arising from audit to be implemented." Despite its brevity this statement exemplifies the NHS Management Executive's emphasis on providing a high quality service and on the need for adequate systems in place to deliver it.
London SW1A 2NS Kenneth C Calman, chief medical officer 


\section{Emphasis on patients}

One example of a range of developments aimed at informing and empowering patients is the establishment in January 1994 of the Health Information Service, giving patients access through a free telephone service to information on common diseases, conditions, and treatments; local health services; waiting times; and how to complain. In this context the patient's charter must be mentioned as a means of setting standards and ensuring that they are met - although scope still exists for standard setting locally - and as an important step forward in ensuring quality of service.

Addressing an agenda across the health service longer term is behind moves to influence the content of training for both professional and non-professional staff so that curricula increasingly include material on quality improvement techniques and attitudes for delivering a patient focused service, and it is encouraging that the education committee of the General Medical Council has recently recommended changing the undergraduate medical curriculum. The current information management and technology strategy is also addressing fundamental issues. The importance of high quality data to support operational and management needs at all levels of the health service cannot be overemphasised. A further valuable contribution is being made by the clinical terms project, which aims at establishing a common clinical language across 40 specialties, is an initiative central to the drive to improve awareness of quality.

Purchasers are now increasingly powerful players in the drive for greater quality. Formerly the "poor relation" of the NHS reforms, purchasing is now growing in strength. Purchasers are looking to achieve health gain and measurable improvements in quality, and are not purchasing on price alone. Keynote speeches by Dr Mawhinney and Sir Duncan Nichol in 1993 have set the tone: clear health targets are beginning to be seen in contracts, and these will feed through into real improvements in quality.

Clinical audit has also taken root as a force for change. The clinical audit policy document, 60000 copies of which have been issued, aims at broadening the audit base and enabling all professions to practise audit and to ensure that care is considered coherently and that audit findings are acted on in a way which is truly patient focused. Real progress is being made here, owing in large part to the work of the Clinical Outcomes Group chaired jointly by the chief medical and chief nursing officers and including representatives of all professional groups and patient representatives. In addition to steering and integrating the audit programme, the group disseminates good practice, advises on action to improve outcomes, and identifies scope for improvements in delivering health care. Such activity is linked to the new drive to promulgate and develop clinical guidelines. Guidelines have of course existed in various forms for many years; the major new initiative will involve working with the professions and the service to identify guidelines which might be used more widely and has the potential to form an essential component of effective purchasing, moving into new areas beyond the Effective Health Care Bulletins.

Such activity relies on a firm research base and is supported by, for example, the recent establishment of the Cochrane Centre to facilitate and coordinate reviews in controlled trials of health of care, and the research and development information transfer centre at the Centre for Health Economics at the University of York.

Taken together, the many current initiatives represent a significant package spanning clinical, professional, and management issues - all underpinned by a strong patient centred focus. "Quality awareness" is a source of good news, and the overall trend is encouraging. 